\title{
Quality of Life and Attitude to Disease in Patients with Bone Tumors
}

\author{
Ekaterina Usmanova ${ }^{1 *}$, Olga Shchelkova², Evgeny Sushentsov ${ }^{3}$, Aslan Valiev $^{3}$ \\ ${ }^{1}$ International Preschool, Moscow, Russia \\ ${ }^{2}$ St. Petersburg State University, Saint Petersburg, Russia \\ ${ }^{3}$ N.N. Blokhin Russian Cancer Research Center, Moscow, Russia
}

\section{ABSTRACT}

The article is devoted to study health-related quality of life and attitude to disease in 120 patients with bone tumor: osteosarcoma (41 persons), giant cell tumor (31 persons), chondrosarcoma (30 persons) and metastatic bone lesion (18 persons).Comparative analysis of quality of life basic parameters, attitude to disease and indices interconnections in four clinical groups of patients was made. Psychological methods were as follows: "SF- 36 Health StatusSurvey», Quality of Life Questionnary-Core 30 of European Organization for Research and Treatment Cancer with module Bone Metastases 22, "The type of relation to disease". The results revealed differences in quality of life parameters, attitude to disease types and differences of correlations between the diagnostics indices in patients with different bone tumor types.

Keywords: Quality of life, relation to disease, bone tumor, osteosarcoma, chondrosarcoma, giant cell tumor, psychological support

\section{INTRODUCTION}

Bone tumors are rare and heterogeneous group of musculo-sceletal diseases. Primary malignant bone tumors are infrequent human tumors. They make less $1 \%$ in the structure of oncological morbidity. The incidence rate of bone sarcomas is 1,03 per 100,000 persons, it is about 1500 new cases per year in Russia (Aliev M.D, 2012). At the same time the frequency of metastatic bone lesion is high. Bone metastases progress in $60-70 \%$ oncological patients.

Since the beginning of 1970-s the growth of survival in patients with bone tumors is revealed (Salsman J.M., 2013). Owing to new chemotherapy, elaboration of bone tumors diagnosis methods and oncological orthopedics

*Correspondence: usmanovakate@ya.ru

Ekaterina Usmanova, International Preschool, Moscow, Russia

Received: 14 February 2018 Accepted: 29 March 2018

Sleep and Hypnosis

Journal homepage:

www.sleepandhypnosis.org

ISSN: 2458-9101 (Online) success most patients may be cured presently. And limb sparing surgery form more than $80 \%$ cases. This makes issue of quality of life current of interest.

Quality of life (QoL) in patients has been studied intensively last decades worldwide. This shows common trend of medicine humanization, intention to develop holistic view of a person and biopsychosocial approach to understanding health and disease. Thereby physicians' attention is fixed not on particular symptoms and disease progression mechanisms, but on a patient as a person with his or her life problems. Health related quality of life concept and methodology are developed fast. In clinical and epidemiological researches quality of life more often is considered a measure of medical intervention efficiency, and in the frame of medicine psychology quality of life during disease represents level and pattern of psychic (physiological, psychological and social) adjustment of person to illness.

Quality of life researches are conducted actively in different medicine fields. A lot of studies are devoted to research quality of life in oncological patients (Dubashi B. et al., 2010; Fagundes C.P. et al., 2013; Koller M., Lorenz W., 2002; Merinsky O. et al., 1997; Osoba D., 1994; 
Tineke V., 2009; Yellen S.B. et al., 1993). There are studies, which reveal significant decline of quality of life different aspects in patients with bone tumor (Bekkering W.P. et al., 2010; Eiser C., Grimer R. J., 1999; Mason G.E. et al., 2013; Morishige M. et al., 2015; Paredes T. et al., 2011; Perisano C. et al., 2015). But that is not enough because most of these studies aim at research quality of life in children and adolescents with bone sarcoma (vanRiel CA et al., 2004; Yonemoto T. et al., 2007). There are also studies aimed at comparative analysis of QoL in patients with bone tumor underwent limb sparing surgery and amputation. (Aksnes LH. et al., 2008; Johansen R. et al., 1998; Robert RS. et al., 2010). While issue of QoL in adults with bone tumor focused on psychological factors of QoL is not discussed. One of the most important components of person adjustment to disease is attitude to disease. In medicine psychology attitude to disease is considered one of the most important subsystems of patient. In the frame of V.N. Myasishev concept of person as a system of significant attitudes psychological analysis supposes consideration of attitude in three semantic aspects: emotional, behavioral and cognitive. In accordance with this, the emotional component of the attitude to disease represents the entire spectrum of feelings caused by the disease, as well as those emotional experiences that arise in situations associated with the disease.

The motivational and behavioral component represent the development of a specific behavioral strategy in life situations in connection with the disease (taking the role of the patient, active confrontation with disease, denial the disease, pessimistic attitudes, etc.), as well as the reactions associated with the disease that promote or hinder adaptation. The cognitive component represents knowledge about the disease, its awareness, understanding of its role and impact on the patient's vital functioning, prognosis. Thus, the psychological analysis of the attitude to disease allows to describe all the main psychic phenomena in which the personality's reaction to the disease manifests itself. At the same time correlations between quality of life parameters and relation to disease in patients with oncological diagnosis have not been studied yet.

The aim of the study was to reveal the basic aspects of QoL and attitude to disease in patients with bone tumors: osteosarcoma, giant cell tumor, chondrosarcoma and bone metastases.

To achieve the aim of the study, the following tasks were set: 1) comparative analysis of basic clinical, psychological and social characteristics, which in total represent QoL during disease in patients with bone tumors; 2) comparative analysis of basic QoL parameters in patients with bone tumors; 3 ) comparative analysis of attitude to disease types in patients with bone tumors; 4) studying of correlations between basic QoL parameters and attitude to disease in patients with bone tumors.

\section{METHOD}

\section{Patients}

Study participants were 120 inpatients of N.N. Blokhin Russian Cancer Research Center. The patients were aged 18 to 67 years old. According the goal of the basic aspects of QoL research general group was split into four groups depending on diagnosis. The groups were: osteosarcoma 41 patients, giant cell tumor (GCT) 31 patients, chondrosarcoma

Table 1. Gender and age in patients with bone tumors

\begin{tabular}{|c|c|c|c|c|c|c|c|c|}
\hline \multirow[t]{2}{*}{ Genderandage } & \multicolumn{2}{|c|}{$\begin{array}{c}\text { OsteoSa }(n=41) \\
\text { A }\end{array}$} & \multicolumn{2}{|c|}{$\begin{array}{c}\text { GCT }(n=31) \\
\text { B }\end{array}$} & \multicolumn{2}{|c|}{$\begin{array}{c}\text { ChondroSa }(n=30) \\
\text { C }\end{array}$} & \multicolumn{2}{|c|}{$\begin{array}{c}\text { Mts }(n=18) \\
D\end{array}$} \\
\hline & $\mathrm{n}$ & $\%$ & $\mathrm{n}$ & $\%$ & $\mathrm{n}$ & $\%$ & $n$ & $\%$ \\
\hline \multicolumn{9}{|l|}{ Gender } \\
\hline Males & 25 & 61 & 13 & 41,9 & 24 & 80 & 14 & 77,8 \\
\hline Females & 16 & 39 & 18 & 58,1 & 6 & 20 & 4 & 22,2 \\
\hline \multicolumn{9}{|l|}{ Average age } \\
\hline Males & \multicolumn{2}{|c|}{$26,7 \pm 1,9$} & \multicolumn{2}{|c|}{$36,1 \pm 1,6$} & \multicolumn{2}{|c|}{$45,4 \pm 0,9$} & \multicolumn{2}{|c|}{$54,9 \pm 1,4$} \\
\hline \multirow[t]{2}{*}{ Females } & \multicolumn{2}{|c|}{$23 \pm 0,8$} & \multicolumn{2}{|c|}{$36 \pm 3$} & \multicolumn{2}{|c|}{$46 \pm 2,6$} & \multicolumn{2}{|c|}{$55 \pm 2,1$} \\
\hline & \multicolumn{2}{|c|}{$33 \pm 3,8$} & \multicolumn{2}{|c|}{$36 \pm 3,2$} & \multicolumn{2}{|c|}{$51 \pm 8,6$} & \multicolumn{2}{|c|}{$55 \pm 5,2$} \\
\hline
\end{tabular}

Note: in table 1 and further: OsteoSa - group of patients with osteosarcoma; GCT - group of patients with giant cell tumor; ChondroSa - group of patients with chondrosarcoma; Mts - group of patients with bone metastases. 
30 patients and bone metastases 18 patients.

Gender and age of patients are given in Table 1.

The data given in Table 1 show, there are differences between groups of patient in age: patients with osteosarcoma are younger than other patients; patient with GCT and chondrosarcoma are middle age people, patients with metastases, in general, are older than 50 years old.

This distribution of patients by age group is typical and is associated with the clinical features of the disease, namely with peaks of incidence of bone tumors different types.

Analysis of social characteristics shows, that most patients with bone tumors have vocational and high education. Most patients with GCT continue professional activity at the moment of the research $(51,6 \%$ and $60,0 \%$ respectively), most patients with osteosarcoma $(51,2 \%)$ and bone metastases $(66,7 \%)$ don't work.

Clinical characteristics of patient are represented in 8 parameters: duration of the disease since diagnosis and since symptoms appearing, stage, treatment, dynamics of disease, complications, surgical treatment, general health status. The assessment of general health status in patients with bone tumor on Karnovsky scale and ECOG is given in Table 2.

\section{Instruments}

1. «SF- 36 Health Status Survey» was used for determining quality of life in patients with bone tumor. 36 items of the questionnaire form 8 scales: General Health (GH), Physical Functioning (PF), RolePhysical (RP), Role-Emotional (RE), Social Functioning (SF), Bodily Pain (BP), Vitality (VT), Mental Health $(\mathrm{MH})$. Scores range from 0 till 100. 100 scores present the best health. The scales form two parameters «physical health» (first four scales) and «mental health» (last four scales) (Ware J.E. et al. 1993;
Wasserman L.I. et al., 2011)

2. «Quality of Life Questionnaire Core-30» was designed by Study Group on Quality of Life of European Organization for Research and Treatment Cancer. The use of QLQ-C30 shows that it is highly sensitive tools for evaluating of quality of life in patients with oncological disease apart from its type. The modern version of EORTC QLQ-C30 includes 30 questions and consists of 5 functional scales (Physical functioning, Role functioning, Emotional functioning, Cognitive functioning, Social functioning), 3 symptom scales (Fatigue, Nausea and vomiting, Pain), Global health status and 6 symptom items (Dyspnoea, Insomnia, Appetite loss, Constipation, Diarrhoea, Financial difficulties) (Aaronson N.K. et al., 1993; Fayers P. et al., 1995)

3. Module BM22 which used for studying of specific symptoms show quality of life in patients with malignant bone tumor. The module consists of 20 questions and has 2 Symptom scales (Painful Sites and Pain Characteristics) and 2 Functional scales (Functional Interference and Psychosocial Aspects) (Aaronson N.K. et al., 1993; Fayers P. et al., 1995)

4. "The type of relation to disease" (TOBOL) aims at revealing attitude to disease in patients. There are 12 types of attitude. The method reveals if the type of disease is adaptive or maladaptive (Wasserman L.I. et al., 2014).

\section{Statistical methods}

Statistical significance of distinctions between groups was calculated with t-criterion Student test. Aimed at studying interconnection of psychodiagnostics parameters correlation analysis was used (Spearman's p-criterion). Statistica 6.0 and Excel XP were used.

Table 2. General health status in patients with bone tumors

\begin{tabular}{|c|c|c|c|c|}
\hline \multirow{2}{*}{$\begin{array}{l}\text { Karnovsky index/ } \\
\text { ECOG scale }\end{array}$} & $\begin{array}{l}\text { Osteosarcoma }(n=41) \\
A\end{array}$ & $\begin{array}{l}\text { Giant cell tumor }(n=31) \\
\text { B }\end{array}$ & $\begin{array}{c}\text { Chondrosarcoma }(n=30) \\
\text { C }\end{array}$ & $\begin{array}{c}\text { Metastases } n=18 \\
\text { D }\end{array}$ \\
\hline & $M \pm m$ & $M \pm m$ & $M \pm m$ & $M \pm m$ \\
\hline Karnovsky index & $80 \pm 1,79$ & $78,89 \pm 2,2$ & $80,5 \pm 2,15$ & $71,18 \pm 2,63$ \\
\hline ECOG scale & $1,23 \pm 0,1$ & $1,41 \pm 0,1$ & $1,4 \pm 0,12$ & $2,12 \pm 0,12$ \\
\hline
\end{tabular}

The results presented in table 2 show, that general health status in patients with primary bone tumor significantly better than general health status in patients with bone metastases $(p<0,05)$. And general health status in patients with different forms of primary bone tumor is the same. 


\section{RESULTS}

At the first stage of the research patients' subjective representation of QoL changing in connection with musculosceletal disease was studied. Patients' relation to disease and treatment, subjective prognosis of disease were also studied. Analysis of differences between clinical groups was done.

Analysis of the results of clinical and psychological research revealed statistical significant differences between groups of patients in the frequency of occurrence of various estimates of changes in $\mathrm{QOL}$ due to the disease $(x 2=49,89 ; p<0,001)$. Most of patients with primary bone tumors assess their quality of life changing as insignificant (53,8\% patients with osteosarcoma, $83,9 \%$ patients with GCT, 56,7\% patients with chondrosarcoma), while a similar assessment was not found in any patient with bone metastases (0\%). 77,8\% patients with bone metastases assess their quality of life changing as significant. This corresponds to objective data on changes in labor status in connection with the disease. None of the patients with primary bone tumors lost ability to work at the moment of research, at the same time $22,2 \%$ patients with bone metastases lost ability to work.

The results of studying relation to disease and treatment revealed that most patients in each of the four groups respond to the disease with denial: $75,6 \%$ patients with osteosarcoma, $54,8 \%$ patients with GCT, $66,7 \%$ patients with chondrosarcoma and $66,7 \%$ patients with bone metastases. Besides most patients with bone tumors have only general image of disease: $78,4 \%$ patients with osteosarcoma, $71,2 \%$ patients with $\mathrm{CCT}, 90,1 \%$ patients with chondrosarcoma and 94,2\% patients with bone metastases.

Most patients with primary bone tumors respond to treatment neutrally (61,0\% patients with osteosarcoma,
$61,3 \%$ patients with GCT and $66,7 \%$ patients with chondrosarcoma. Most patients with bone metastases respond to disease positively $(66,7 \%)$. This is due to the fact that for the majority of patients with primary bone tumors with the understanding of the need for treatment surgery and rehabilitation after it are seen as complicating life and undesirable. Patients with bone metastases, despite the severity of treatment, see it as a hope for life extension and painful procedures do not frighten them and do not seem to burden them against the background of a progressing tumor.

There were not statistically significant differences between groups of patients on the indices of relation to disease and treatment. Withal high statistically significant differences between groups of patients were revealed on patients' esteem of treatment prospects (Table 3).

Table 3 shows, that most patients with GCT are turned to complete cure, whereas among patients with osteosarcoma only $35,0 \%$ patients consider treatment prospects as complete cure, and among patients with chondrosarcoma $16,7 \%$ patients are turned to complete cure. Among patients with bone metastases, there were no people who expect complete recovery. The majority of patients with chondrosarcoma and bone metastases expect health improvement.

According the goals of the research at the next phase there were studied characteristics of quality of life related to general health in patients with bone tumors (Table 4) and characteristics of quality of life related to oncological disease and directly with bone tumors (Table 5).

According the results of SF-36 patients with bone metastases assess significantly lower their general health and treatment prospects, than patients with primary bone tumor. Patients with primary bone sarcoma have lower

Table 3. Distribution of patients with bone tumors by theiresteem of treatment prospects

\begin{tabular}{|c|c|c|c|c|c|c|c|c|}
\hline \multirow{2}{*}{$\begin{array}{l}\text { Patients' esteem of } \\
\text { treatment prospects }\end{array}$} & \multicolumn{2}{|c|}{$\begin{array}{c}\text { OsteoSa }(n=41) \\
A\end{array}$} & \multicolumn{2}{|c|}{$\begin{array}{c}\text { GCT }(n=31) \\
\text { B }\end{array}$} & \multicolumn{2}{|c|}{$\begin{array}{c}\text { ChondroSa }(n=30) \\
\text { C }\end{array}$} & \multicolumn{2}{|c|}{$\begin{array}{c}\text { Mts }(n=18) \\
D\end{array}$} \\
\hline & $\mathbf{n}$ & $\%$ & $\mathbf{n}$ & $\%$ & $\mathbf{n}$ & $\%$ & $\mathbf{n}$ & $\%$ \\
\hline Health impairment & 5 & 12,5 & 1 & 3,2 & 1 & 3,3 & 2 & 11,1 \\
\hline Health maintenance at the current level & 2 & 5 & 0 & 0 & 2 & 6,7 & 1 & 5,6 \\
\hline Health improvement & 19 & 47,5 & 7 & 22,6 & 22 & 73,3 & 15 & 83,3 \\
\hline Cure & 14 & 35 & 23 & 74,2 & 5 & 16,7 & 0 & 0 \\
\hline \multicolumn{9}{|c|}{$\chi^{2}=38,7 \quad p<0,001$} \\
\hline
\end{tabular}


Table 4. Quality of life related to general health in patients with bone tumors

\begin{tabular}{|c|c|c|c|c|c|}
\hline SF-36 scales & $\begin{array}{c}\text { OsteoSa }(n=41) \\
A\end{array}$ & $\begin{array}{c}\mathrm{GCT}(\mathrm{n}=31) \\
\text { B }\end{array}$ & $\begin{array}{c}\text { ChondroSa }(n=30) \\
\text { C }\end{array}$ & $\begin{array}{c}\text { Mts }(n=18) \\
\text { D }\end{array}$ & Post Hoc \\
\hline General Health & $59,7 \pm 3,2$ & $58 \pm 2,6$ & $58,6 \pm 3,8$ & $49,6 \pm 5,8$ & $A D^{*}$ \\
\hline Role-Physical & $33,1 \pm 6,1$ & $22,6 \pm 6,7$ & $40 \pm 8,1$ & $19,4 \pm 8,5$ & $\begin{array}{l}B C^{*} \\
C D^{*}\end{array}$ \\
\hline $\begin{array}{l}\text { Role-Emotional } \\
\text { Bodily Pain }\end{array}$ & $\begin{array}{l}47,5 \pm 6,9 \\
52,8 \pm 4,8\end{array}$ & $\begin{array}{l}48,4 \pm 7,9 \\
47,5 \pm 4,9\end{array}$ & $\begin{array}{l}58,9 \pm 8,1 \\
47,1 \pm 5,1\end{array}$ & $\begin{array}{c}35,2 \pm 10,2 \\
36,5 \pm 4,4\end{array}$ & $\begin{array}{c}C D^{\star} \\
A D^{\star * *} B D^{\star} C D^{\star}\end{array}$ \\
\hline Vitality & $62,1 \pm 3,5$ & $60,5 \pm 2,8$ & $63,7 \pm 4,4$ & $48,3 \pm 5,6$ & $\begin{array}{c}A D^{* *} \\
B D^{* *} C D^{\star *}\end{array}$ \\
\hline
\end{tabular}

Note. In this table and subsequent ones in the column "Reliable Differences" sign *corresponds to the level of statistical significance $0,05<p<0,1 ; * \star-p<0,05 ;{ }^{* \star \star}-p<0,01$. According SF-36 large values of scoring assessments correspond to better quality of life characteristics. For instant, high scores of scale "Bodily Pain" means that pain syndrome slightly limits patients' vital activity and social functioning. The maximum score for all scales is 100.

Table 5. Differences in QoL parameters in patients with bone tumors

\begin{tabular}{|c|c|c|c|c|c|}
\hline EORTC QLQ C-30 scales & $\begin{array}{c}\text { OsteoSa }(n=41) \\
A\end{array}$ & $\begin{array}{c}\text { GCT }(n=31) \\
\text { B }\end{array}$ & $\begin{array}{c}\text { ChondroSa }(n=30) \\
\text { C }\end{array}$ & $\begin{array}{c}\text { Mts }(n=18) \\
\text { D }\end{array}$ & Post Hoc \\
\hline General health & $56,3 \pm 3,5$ & $47,9 \pm 4$ & $52,8 \pm 5,9$ & $43,5 \pm 5,8$ & $A D^{* *} A B^{*}$ \\
\hline Physical functioning & $65,7 \pm 3,7$ & $63,2 \pm 4,1$ & $68,6 \pm 4,8$ & $57,8 \pm 6,4$ & $C D^{*}$ \\
\hline Rolefunctioning & $56,91 \pm 5,3$ & $52,2 \pm 5,5$ & $62,4 \pm 6,1$ & $46,3 \pm 7,7$ & $C D^{*}$ \\
\hline Social functioning & $64,6 \pm 5,6$ & $56,5 \pm 5$ & $72,8 \pm 5,8$ & $55,6 \pm 8,1$ & $\begin{array}{l}B C^{\star *} \\
C D^{* *}\end{array}$ \\
\hline Pain & $39,4 \pm 5,1$ & $52,2 \pm 5,9$ & $49,4 \pm 6,3$ & $60,2 \pm 6,1$ & $\begin{array}{c}A B^{\star} C D^{*} \\
A D^{\star \star *}\end{array}$ \\
\hline Dispnoe & $21,1 \pm 4,7$ & $12,9 \pm 4,1$ & $18,5 \pm 5,8$ & $37 \pm 8,23$ & $\begin{array}{c}\mathrm{AD}^{*} \mathrm{CD}^{*} \\
\mathrm{BD} * \star *\end{array}$ \\
\hline Insomnia & $33,3 \pm 5,1$ & $35,5 \pm 5,7$ & $44,4 \pm 7$ & $48,2 \pm 7,9$ & $A D *$ \\
\hline & \multicolumn{5}{|c|}{ ModuleQLQ-BM22 scales } \\
\hline Pain sites & $18,5 \pm 1,9$ & $24,7 \pm 3,3$ & $22,9 \pm 4,1$ & $30,7 \pm 3,1$ & $\begin{array}{l}A B^{*} C D^{*} \\
A D^{\star * *}\end{array}$ \\
\hline Pain characteristics & $25,5 \pm 4,9$ & $32,9 \pm 4,7$ & $33,8 \pm 5,3$ & $38,9 \pm 5,6$ & $\begin{array}{c}A D^{*} \\
A D^{* * *}\end{array}$ \\
\hline Functional interferences & $67,1 \pm 4,4$ & $60,9 \pm 3,9$ & $62,7 \pm 5,3$ & $46,5 \pm 5,7$ & $\begin{array}{l}\mathrm{BD}^{* *} \\
\mathrm{CD} \mathrm{D}^{\star *}\end{array}$ \\
\hline
\end{tabular}

Note:in method EORTC QLQ C-30 for functional scales and for scale of general health the highest QoL corresponds to 100 score, the worst - 0. For all symptom scales health the highest QoL corresponds to 0, the worst - - 100 score (Fayers P. et al., 1995).

influence of their physical state on daily activities, than patients with giant cell tumor and bone metastases. Besides Patients with bone metastases have more restricted activity caused pain intensity and have lower vitality than patients with primary bone tumor.

The results of studying QoL using QLQC-30 with module BM 22 in patients with bone tumor are given in Table 5.

These data are consistent and complimentary with the results of studying health related quality of life researched using SF-36. QLQ C-30 questionnaire was designed as method for quality of life assessment especially in patients with malignant tumor. Using QLQ C-30 differences in the patient assessment of general health were revealed. Patients with bone metastases and giant cell tumor assess their

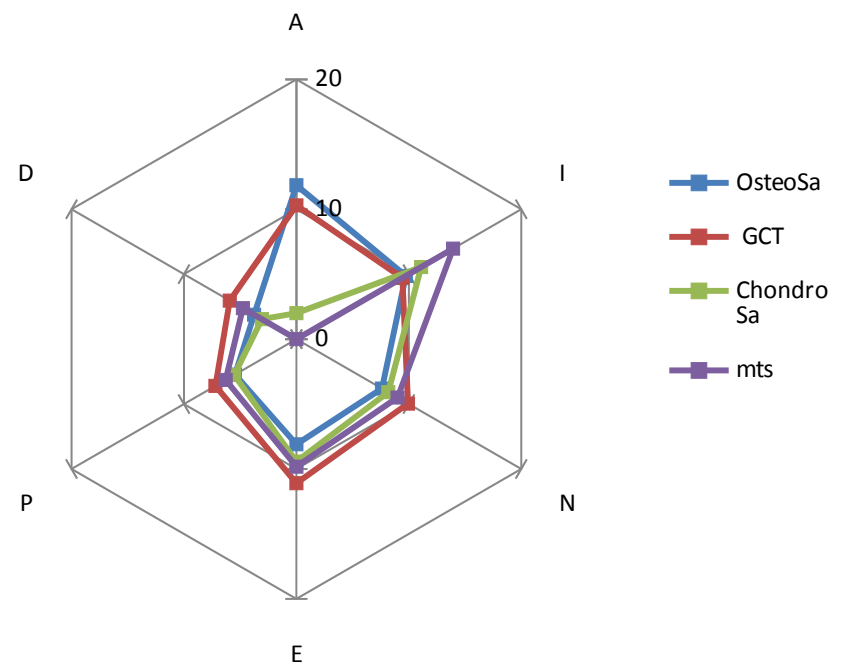

Figure 1. Attitude to disease in patients with bone tumors 
health significantly worse than patients with osteosarcoma.

Patients with chondrosarcoma have higher physical functioning and less restricted in daily activities than patients with bone metastases. Social functioning in patients with chondrosarcoma is also higher than in patients with bone metastases and giant cell tumor.

The study using special module of QLQ questionnaire "bone metastases" revealed that patients with bone metastases have the most intensity pain among all patients. Patients with bone metastases characterize their pain as more widespread and intensive than patients with primary bone tumor.

The results of studying attitude to disease in patients with bone tumor are given in Figure 1.

Fig. 1 shows, that patients with osteosarcoma and giant cell tumor more often react to disease on denial (anosognotic) type. They are inclined to reject thoughts about the disease and its possible consequences, up to the denial of the obvious ones; they have desire to continue living like earlier, despite the disease, as well as the ease of violations of the regime and medical recommendations, adversely affecting the course of the disease.

Patients with bone metastases more often react to disease on hypochondriacal type. They are prone to excessive concentration on subjective painful sensations. They have desire to be cured and disbelief in success. Patients with bone metastases (related to the last stage of the disease) usually have poor prognosis, in addition, there is a myth in the society that metastasis means "death sentence". Thus, lack of faith in success of treatment in patients with bone metastases is clear.

In the group of patients with giant cell tumor, the neurasthenic, egocentric and paranoid types of attitude to disease are greater than among patients with osteosarcoma, which indicates the tendency of patients with giant cell tumor to behave like "irritable weakness" and to seek a "secondary benefit" from their disease. They are sure that their disease is the result of external causes, someone's malice or bad faith, incompetence. Also, among patients with giant cell tumor, the dysphoric type of attitude to disease is significantly more pronounced than in the group of patients with osteosarcoma and chondrosarcoma: patients with giant cell tumor are characterized by a gloomy mood, envy and aggression towards healthy people.

Aimed at reveal interconnections between QoL parameters and attitude to disease in patients with bone tumor correlation analysis was done.

The results of studying interconnections between QoL parameters (SF-36 results) and attitude to disease in patients with osteosarcoma revealed that index of the "General Health" scale in patients with osteosarcoma negatively correlates with the indices of hypochondriacal $(p<0,05)$, apathetic $(p<0,05)$ and egocentric $(p<0,05)$ types of attitude to disease. Consequently, based on the results of comparative analysis, revealed, that with the same physical status, patients of different clinical groups are characterized by different quality of life and at the same time differ in their attitude towards the disease, we could assume, that response to disease with hypochondriac, apathetic and egocentric types, classified as nonadaptive, significantly worsens the subjective assessment of the quality of life associated with the general health status.

Besides index of scale "Role-Emotional" positively correlates with anosognotic $(p<0,05)$ attitude to disease and negatively correlates with the indices of anxious $(p<0,05)$, neurasthenic $(p<0,05)$, apathetic $(p<0,05)$ and dysphoric $(p<0,05)$ attitude to disease; the less the disease affects the emotional state of the patient, the more he is inclined to deny its severity and consequences, and the less he is inclined to mood changing in anxious type, by the type of "irritable weakness" or by the type of loss of interest in life. The same correlations were revealed for the scale "Social functioning": higher level of social activity corresponds to higher severity of anosognosic type of attitude to disease and less severity of anxious, neurasthenic, apathetic and egocentric types.

The index of scale "Bodily Pain" in patients with osteosarcoma positively correlates with anosognotic $(p<0,05)$ attitude to disease and negatively correlates with the indices of neurasthenic $(p<0,05)$, apathetic $(p<0,01)$ and egocentric $(p<0,05)$ types of attitude to disease. The less pain limits patients' daily activity, the more they are inclined to deny the illness. Simultaneously, the greater influence of pain on patients' vital functioning is accompanied by increasing asthenic manifestations, 
irritability and, especially, apathy as well could be accompanied by demonstrative desire to arouse sympathy, attract the attention of others.

The index of "Mental Health" scale naturally negatively correlates with the indices of anxious $(p<0,05)$, hypochondriac $(p<0,05)$, neurasthenic $(p<0,01)$, sensitive $(p<0,05)$ and dysphoric $(p<0,05)$ attitude to disease.

The results of studying interconnections between QoL parameters (QLQ C-30 and BM-22 results) and attitude to disease in patients with osteosarcoma revealed that index of the "Physical Functioning" negatively correlates with the indices of nonadaptive attitudes to disease such as hypochondriac $(p<0,05)$, melancholic $(p<0,05)$ and apathetic $(p<0,05)$ types.

The results of studying interconnections between QoL parameters (SF-36, QLQ C-30 and BM-22 results) and attitude to disease in patients with $G C T$ revealed wide high significant correlations between the index of the scale "Role Emotional" and the indices of attitude to disease. Positive correlation of this index with the index of ergopathic ("escape to work") attitude to disease $(p<0,01)$ shows that fewer emotional problems are experienced by patients who tend to maintain their former (before disease) professional status in a compensatory manner, the format and scope of their work.

At the same time, emotional problems naturally increase in persons with anxious $(p<0,01)$, hypochondriac $(p<0,05)$, egocentric $(p<0,01)$ and paranoid $(p<0,01)$ types of attitude to disease.

The results revealed interconnections between quality of life related to bone tumors and relation to disease on the parameter "Emotional functioning". Preservation of natural emotional connections, differentiated character of emotional response in different situations is combined with harmonious $(p<0,01)$ and ergopathic $(p<0,01)$ types of attitude to disease. On the contrary, anxious $(p<0,01)$, neurasthenic (type of "irritable weakness") $(p<0,05)$ and egocentric $(p<0,05)$ attitudes to disease impoverish character of emotional response in patients, fixing patients on the experiences associated with disease.

Quality of life parameter "Mental Health" has the same correlations: greater well-being in all spheres of mental life corresponds to harmonious type of attitude to disease $(p<0,05)$. And problems of mental functioning accrue with the increasing role of anxious $(p<0,05)$, neurasthenic $(p<0,05)$ and apathic $(p<0,05)$ components in the structure of attitude to oncological disease.

The results of studying interconnections between general QoL parameters (SF-36 results) and attitude to disease in patients with chondrosarcoma revealed difference of correlations structure in patients with chondrosarcoma compared with correlations structure in patients with osteosarcoma and GCT.

It is noteworthy that all indices of QoL negatively correlate with index of apathetic attitude to disease $(p<0,01)$, objectifying the tendency of patients with chondrosarcoma to "give up" in the process of treatment, lack of faith in treatment success and indifference to other aspects of life. The majority of QoL indices also negatively correlate with indices of paranoid $(p<0,01)$ and dysphoric $(p<0,01)$ attitude to disease. Quality of life in the situation of illness worsens on the background of suspicious, irritable, despotic attitude to persons of the nearest social environment.

Quality of life parameter "Mental Health" has the most interconnections with relation to disease: harmonious attitude to disease is combined with an optimal level of mental health $(p<0,01)$. And problems of mental functioning accrue with the increasing role of melancholic $(p<0,01)$, neurasthenic $(p<0,05)$ and especially apathic $(p<0,01)$ and paranoid $(p<0,01)$ components in the structure of attitude to disease. At the same time, it is obvious that the severity of disadaptive types of attitude to disease can be determined by a violation of the mental status in patients being in a situation of chronic emotional stress because of disease. Thus, the severity of mental illbeing and disadaptive attitudes to disease can have the character of ring dependencies and potentiate each other.

In the structure of interconnections of quality of life related to bone tumors (QLQ C-30 and BM-22 results) as well as on the parameters of general quality of life correlations with paranoid $(p<0,01)$ and dysphoric $(p<0,01)$ attitude to disease dominate. These types of attitude to disease relate to disadaptive attitudes, i.e. the focus on the external environment, which is perceived as hostile, that generates suspicion, aggressiveness, despotism 
or envy of the closest environment. These tendencies increase with intensification and expansion of pain sites, as evidenced by the corresponding high statistically significant positive interrelations between the parameters of paranoid and dysphoric attitudes to disease, on the one hand, and QoL indices "Pain sites" $(p<0,01)$ and "Pain characteristics" $(p<0,01)$, on the other hand.

The results of studying interconnections between QoL parameters (SF-36 results, QLQ C-30 and BM-22 results) and attitude to disease in patients with bone metastases revealed correlations attitude to disease and indices of QoL scales "Vitality", "Role Emotional", "Social Functioning" and "Mental Health".

In all cases, there were negative correlations between QoL parameters and indices of maladaptive attitude to disease (hypochondriacal, neurasthenic, melancholic types) $(p<0,05)$. There were also positive correlations with indices of adaptive attitude (harmonious, ergopatic and anosognosic types) $(p<0,05)$. We could conclude that the feeling of full strength and energy is correlated in patients with optimistic attitude to life, with an assessment of their condition without a tendency to exaggerate its severity, but also without underestimating the severity of the disease, as well as with "escape into work "and active rejection of thoughts about disease.

Feeling exhausted in a group of patients with bone metastases corresponds with exaggeration of disease severity, irritation, gloomy mood and indifference to the outcome of the disease.

\section{CONCLUSION}

Currently, there is a variety of concepts and psychological constructs reflecting subjective component of clinical picture of disease, possible personality responses to disease, personal meaning of disease and satisfaction with quality of life in the situation of disease. Such constructs are created not only for theoretical comprehension of relationship between person and disease. They have a significant practical significance for the purposes of psychotherapy aimed at changing inadequate responses of the individual to the disease, creating realistic attitudes in patients for treatment, restoring social ties in the immediate and wider environment.

For medical psychology, the concept of attitude to disease is one of the most important in the system of personality relations, and also an important component of psychological adjustment. Person's attitude to disease takes on the role of reflection of patient's thoughts and behavior, emotional status and relations with people. The attitude to disease of patient impacts on disease course, treatment and medical prognosis.

The results revealed that quality of life and general health status in patients with primary bone tumor significantly better than quality of life and general health status in patients with bone metastases. There are differences in QoL parameters between patients with primary bone tumor: patients with giant cell tumor have the worst QoL among patients with primary bone tumor and the same general health status. Patients with bone tumors also differ in attitude to disease. Patients with osteosarcoma more often response to disease on denial type, patients with giant cell tumor - on neurasthenic, egocentric, paranoid and dysphoric types of attitude to disease, patients with bone metastases more often response to disease on hypochondriacal type.

We could assume that these attitudes to disease can be formed in the situation of oncological disease by neurotic mechanisms in connection with ingrained disturbed interpersonal relationships or intrapersonal conflicts.

These results may be used in making programs of psychological helping in patients with bone tumors.

Besides the results of studying correlations between quality of life and attitude to disease, in turn, can supplement and develop views of medical psychology about mechanisms of personality adjustment to severe situation of oncological disease.

Acknowledgments: None declared.

Conflict of interest: The authors declare no conflict of interest.

Informed consent: Informed consent was obtained from all the participants included in the study.

Funding: The research is supported with RFFI grant № 17-36-00011 


\section{References}

Aaronson N.K., Meyerowitz B.E., Bard M. (1991). Quality of life research in oncology. Cancer (Philad), 67, 839-843.

Aksnes L.H., Bauer H.C., Jebsen N.L., Follerås G., Allert C., Haugen G.S., Hall K.S. (2008). Limb-sparing surgery preserves more function than amputation: a Scandinavian sarcoma group study of 118 patients. J. Bone Joint Surg. Br.,90(6),786-794.

Aliev M.D., Sushentsov E.A. (2012). Modern oncoorthopaedy. J. Sarcomas of bone, soft tissue and tumors of skin, 4, 3-10.

Bekkering W.P., Vlieland T.P., Koopman H.M., Schaap G.R., Schreuder H.W., Beishuizen A., Tissing W.J., Hoogerbrugge P.M., Anninga J.K., Taminiau A.H. (2010). Quality of life in young patients after bone tumor surgery around the knee joint and comparison with healthy controls.Pediatr Blood Cancer, 54(5),738-745.

Dubashi B., Vidhubala E., Cyriac S., Sagar TG. (2010). Quality of life among young women with breast cancer: Study from a tertiary institute in south India. Indian J. Cancer,47,142-147.

Eiser C., Darlington A.E., Stride S.B., Grimer R. J. (2001). Quality of life implications as a consequence of surgery: limb salvage, primary and secondary amputation. Sarcoma, 5, 189-195.

Eiser C., Grimer R. J. (1999). Quality of life in survivors of a primary bone tumor: a systematic review. Sarcoma, 183-190.

Fagundes C.P., Lindgren M.E., Kiecolt-Glaser J.K. (2013). Psychoneuroimmunology and cancer: Incidence, Progression, and Quality of life. Psychological aspects of cancer, 1-11.

Johansen R., Nielsen O.S., Keller J. (1998). Functional outcome in sarcomas treated with limb-salvage surgery or amputation. Sarcoma, 2(1),19-23.

Koller M., Lorenz W. (2002). Quality of life: a deconstruction for clinicians. J. R. Soc. Med, 95, 481-488.

Mason G.E., Aung L., Gall S., Meyers P.A., Butler R., Krüg S., Kim M., Healey J.H., Gorlick R. (2013). Quality of life following amputation or limb preservation in patients with lower extremity bone sarcoma. Front. Oncol, 14,3-210.

Merinsky O., Kollender Y., Inbar M. et al. (1997). Palliative major amputation and quality of life in cancer patients.Acta Oncology, $36(2), 151-157$.
Morishige M., Muramatsu K., Tominaga Y. (2015). Surgical treatment of metastatic femoral fractures: achieving an improved quality of life for cancer patients. Anticancer Res, 35(1),427-432.

Osoba D. (1994). Lessons learned from measuring health-related quality of life in oncology. J. Clin. Oncol, 12,608-616.

Paredes T., Pereira M., Moreira H., Simões M.R., Canavarro M.C. (2011).Quality of life of sarcoma patients from diagnosis to treatments: predictors and longitudinal trajectories. Eur. J. Oncol. Nurs,15(5),492-499.

Perisano C., Scaramuzzo L., De Santis V. (2015). Quality of life following surgical treatment of lower limb metastases in long bone. J. Biol. Regul. Homeost. Agents.,29(2), 501-507.

Robert R.S., Ottaviani G., Huh W.W., Palla S., Jaffe N. (2010). Psychosocial and functional outcomes in long-term survivors of osteosarcoma: a comparison of limb-salvage surgery and amputation. Pediatr Blood Cancer, 54(7),990-999.

Tineke V. (2009). Denial and Quality of Life in Lung Cancer Patients, 10

van Riel C.A., Meijer-van den Bergh E.E., Kemps H.L., Feuth T. Schreuder H.W., Hoogerbrugge P.M., De Groot I.J., MavinkurveGroothuis A.M. (2014). Self-perception and quality of life in adolescents during treatment for a primary malignant bone tumour. Eur. J. Oncol. Nurs,18(3),267-272.

Ware J.E., Snow K. K., Kosinski M., Gandek B. (1993). SF-36 Health Survey Manual and Interpretation Guide, The Health Institute.

Wasserman, L. I., Trifonova, E. A., \&Shelkova A. Yu. (2011). Psychological diagnostics and intervention in somatic clinic. Saint Petersburg: Rech.

Yellen S.B., Cella D.F., Bolomi A. (1993). Quality of life in people with Hodgkin's disease. Oncology, 7,41.

Yonemoto T., Ishii T., Takeuchi Y., Kimura K., Hagiwara Y., Iwata S., Tatezaki S.-I. (2007). Evaluation of Quality of Life (QOL) in Long-term Survivors of High-grade Osteosarcoma: A Japanese Single Center Experience. Anticancer Research, 27, 3621-3624. 